\title{
Occipital Condyle-C1 Complex Screw for Fixation of Basilar Invagination Patients with Atlas Assimilation
}

\author{
Kazım YIGITKANLI' ${ }^{1}$, Serkan SIMSEK² \\ ${ }^{1}$ Polatli Government Hospital, Neurosurgery Clinic, Ankara, Turkey \\ ${ }^{2}$ Lokman Hekim Hospital, Neurosurgery Clinic, Ankara, Turkey
}

To the Editor;

W e've read with great interest the recent article by Tong et al. (1). In this article the authors report on C1-occipital condyle complex (CC complex) screw fixation technique in basilar invagination patients with atlas assimilation. The authors report eight consecutive patients operated via this technique combined with $\mathrm{C} 2$ pedicle screw fixation. Tong and colleagues performed the reduction of this deformity with applying power on $\mathrm{CC}$ complex-C2 pedicle screw which was shown at Figure 2 of this article (1). At the follow up period of this series, none of the patients had implant failure with successful fusion.

The same group reported their experience of posterior reduction of the fixed atlantoaxial dislocation (AAD) and basilar invagination $(\mathrm{BI})$ by atlantoaxial facet joint release and fixation in larger series $(3,4)$. They also stated that the irreducible nature of $A A D$ and $B I$ is due to the olisthy of the atlantoaxial facet joint and this malalignment can be reduced after opening the $\mathrm{C} 1-\mathrm{C} 2$ facet joint which guarantees longer bone purchase with immediate stabilization (3).

Even the main aim of this article was to describe the safe and rapidly placement of the $\mathrm{CC}$ complex screw fixation technique, facet joint release was not described at the published article (1). It should be discussed why it was not performed or if it was, should be added to the surgical technique by the authors.

We strongly believe that facet joint release is the key surgical procedure addressing the etiology of deformity at $\mathrm{BI}$ with AAD which may also help to perform better reduction of the deformity, without implant failure at long term follow-up.

Additionally, when describing their technique and discussing the main difference between the CC complex screw and the condylar screw procedure, Tong et al. stated the location of the horizontal segment (V3) of the vertebral artery (VA) between the lower edge of the foramen magnum and $\mathrm{C} 2$, additionally showed this at their Figure 1A (1).

Wang et al. classified variations in VA in the presence of an occipitalized atlas into fourty peson 36 patients and 72 VAs (2). Type I, wherein the VA enters the spinal canal below the C1 posterior arch, and the course of the VA is below the occipitalized C1 lateral mass (8.3\% of 72 vertebral arteries); Type II, the VA enters the spinal canal below the C1 posterior arch, and the course of the VA is on the posterior surface of the occipitalized $\mathrm{C} 1$ lateral mass, or makes a curve on it (25\%); Type III, wherein the VA ascends externally laterally after leaving the axis transverse foramen, enters an osseous foramen created between the atlas and occipital bone, then into the cranium (61.1\%, most common variety); and Type IV, in which the VA is absent (5.6\%).

CC complex screw fixation can be dangerous in cases of a persistent first intersegmental artery where the VA courses abnormally below the C1 posterior arch [type I or II of Wang's classification (2)], and if we look for this variety bilaterally, it is not seen more than $14 \%$ in Wang's series, which is very different from the published article by Tong et al. (1).

Based on this knowledge, detailed preoperative investigation of the VA course should be undertaken before CC complex screw fixation technique.

\section{- REFERENCES}

1. Tong H, Li L, Yu XG, Zhang Y, Peng W: Occipital condyle-C1 complex screw for fixation of basilar invagination patients with atlas assimilation. Turk Neurosurg 26:758-762, 2016

2. Wang S, Wang C, Liu Y, Yan M, Zhou H: Anomalous vertebral artery in craniovertebral junction with occipitalization of the atlas. Spine (Phila Pa 1976) 34:2838-2842, 2009

3. Yin YH, Tong HY, Qiao GY, Yu XG: Posterior reduction of fixed atlantoaxial dislocation and basilar invagination by atlantoaxial facet joint release and fixation: A modified technique with 174 cases. Neurosurgery 78: 391-400; discussion 400, 2016

4. Yin $Y H, Y u X G$, Qiao GY, Guo SL, Zhang JN: C1 lateral mass screw placement in occipitalization with atlantoaxial dislocation and basilar invagination: A report of 146 cases. Spine (Phila Pa 1976) 39: 2013-2018, 2014 